NASA/CR—2008-215289

\title{
CFD Modeling of Superheated Fuel Sprays
}

\author{
M.S. Raju \\ ASRC Aerospace Corporation, Cleveland, Ohio
}




\section{NASA STI Program . . . in Profile}

Since its founding, NASA has been dedicated to the advancement of aeronautics and space science. The NASA Scientific and Technical Information (STI) program plays a key part in helping NASA maintain this important role.

The NASA STI Program operates under the auspices of the Agency Chief Information Officer. It collects, organizes, provides for archiving, and disseminates NASA's STI. The NASA STI program provides access to the NASA Aeronautics and Space Database and its public interface, the NASA Technical Reports Server, thus providing one of the largest collections of aeronautical and space science STI in the world. Results are published in both non-NASA channels and by NASA in the NASA STI Report Series, which includes the following report types:

- TECHNICAL PUBLICATION. Reports of completed research or a major significant phase of research that present the results of NASA programs and include extensive data or theoretical analysis. Includes compilations of significant scientific and technical data and information deemed to be of continuing reference value. NASA counterpart of peer-reviewed formal professional papers but has less stringent limitations on manuscript length and extent of graphic presentations.

- TECHNICAL MEMORANDUM. Scientific and technical findings that are preliminary or of specialized interest, e.g., quick release reports, working papers, and bibliographies that contain minimal annotation. Does not contain extensive analysis.

- CONTRACTOR REPORT. Scientific and technical findings by NASA-sponsored contractors and grantees.

- CONFERENCE PUBLICATION. Collected papers from scientific and technical conferences, symposia, seminars, or other meetings sponsored or cosponsored by NASA.

- SPECIAL PUBLICATION. Scientific, technical, or historical information from NASA programs, projects, and missions, often concerned with subjects having substantial public interest.

- TECHNICAL TRANSLATION. Englishlanguage translations of foreign scientific and technical material pertinent to NASA's mission.

Specialized services also include creating custom thesauri, building customized databases, organizing and publishing research results.

For more information about the NASA STI program, see the following:

- Access the NASA STI program home page at http://www.sti.nasa.gov

- E-mail your question via the Internet to help@ sti.nasa.gov

- Fax your question to the NASA STI Help Desk at 301-621-0134

- Telephone the NASA STI Help Desk at 301-621-0390

- Write to: NASA Center for AeroSpace Information (CASI) 7115 Standard Drive Hanover, MD 21076-1320 


\title{
CFD Modeling of Superheated Fuel Sprays
}

\author{
M.S. Raju \\ ASRC Aerospace Corporation, Cleveland, Ohio
}

Prepared for the

47th Aerospace Sciences Meeting

sponsored by the American Institute of Aeronautics and Astronautics

Orlando, Florida, January 5-8, 2009

Prepared under Grant NNC06BA07B, Task order 22

National Aeronautics and

Space Administration

Glenn Research Center

Cleveland, Ohio 44135 


\section{Acknowledgments}

The research funding for this work was provided by NASA Glenn Research Center with Dr. N.-S. Liu acting as the technical monitor.

This report is a preprint of a paper intended for presentation at a conference.

Because changes may be made before formal publication, this preprint is made available with the understanding that it will not be cited or reproduced without the permission of the author.

This work was sponsored by the Fundamental Aeronautics Program at the NASA Glenn Research Center.

Level of Review: This material has been technically reviewed by NASA technical management.

Available from

NASA Center for Aerospace Information 7115 Standard Drive

Hanover, MD 21076-1320
National Technical Information Service 5285 Port Royal Road Springfield, VA 22161

Available electronically at http://gltrs.grc.nasa.gov 


\title{
CFD Modeling of Superheated Fuels Sprays
}

\author{
M.S. Raju \\ ASRC Aerospace Corporation \\ Cleveland, Ohio 44135
}

\begin{abstract}
An understanding of fuel atomization and vaporization behavior at superheat conditions is identified to be a topic of importance in the design of modern supersonic engines. As a part of the NASA aeronautics initiative, we have undertaken an assessment study to establish baseline accuracy of existing CFD models used in the evaluation of a flashing jet. In a first attempt towards attaining this goal, we have incorporated an existing superheat vaporization model into our spray solution procedure but made some improvements to combine the existing models valid at superheated conditions with the models valid at stable (non-superheat) evaporating conditions. Also, the paper reports some validation results based on the experimental data obtained from the literature for a superheated spray generated by the sudden release of pressurized R134A from a cylindrical nozzle. The predicted profiles for both gas and droplet velocities show a reasonable agreement with the measured data and exhibit a self-similar pattern similar to the correlation reported in the literature. Because of the uncertainty involved in the specification of the initial conditions, we have investigated the effect of initial droplet size distribution on the validation results. The predicted results were found to be sensitive to the initial conditions used for the droplet size specification. However, it was shown that decent droplet size comparisons could be achieved with properly selected initial conditions, For the case considered, it is reasonable to assume that the present vaporization models are capable of providing a reasonable qualitative description for the two-phase jet characteristics generated by a flashing jet. However, there remains some uncertainty with regard to the specification of certain initial spray conditions and there is a need for experimental data on separate gas and liquid temperatures in order to validate the vaporization models based on the Adachi correlation for a liquid involving
\end{abstract}

R134A.

\section{NOMENCLATURE}

$\begin{array}{ll}B_{k} & \text { Spalding mass transfer number } \\ B_{t} & \text { Spalding heat transfer number } \\ C_{p} & \text { specific heat, } \mathrm{J} /(\mathrm{kg} \mathrm{K}) \\ d & \text { droplet diameter, } \mathrm{m} \\ d t & \text { time increment, } \mathrm{s} \\ h & \text { specific enthalpy, } \mathrm{J} / \mathrm{kg} \\ k & \text { thermal conductivity, } \mathrm{J} /(\mathrm{ms} \mathrm{K}) \\ l_{k} & \text { mixture latent heat of evaporation, } \mathrm{J} / \mathrm{kg} \\ l_{k, \text { eff }} & \text { effective latent heat of evaporation, } \\ & \text { J/kg (defined in Eq. }(6)) \\ \dot{m} & \text { liquid mass flow rate, } \mathrm{kg} / \mathrm{s} \\ \dot{m} k, f l a s h & \text { droplet vaporization rate under } \\ & \text { flash evaporating conditions, } \mathrm{kg} / \mathrm{s} \\ \dot{m}_{k, t} & \text { droplet vaporization rate due } \\ & \text { to heat transfer, } \mathrm{kg} / \mathrm{s} \\ n_{k} & \text { number of droplets in } \mathrm{kth} \text { group } \\ N u & \text { Nusselt number } \\ P & \text { pressure, } \mathrm{N} / \mathrm{m}^{2} \\ P r & \text { Prandtl number } \\ P_{s a t} & \text { saturation pressure, } \mathrm{N} / \mathrm{m}^{2} \\ r_{k} & \text { droplet radius, } \mathrm{m} \\ R_{u} & \text { gas constant, } \mathrm{J} /(\mathrm{kg} \mathrm{K}) \\ R e & \text { Reynolds number } \\ S h & \text { Sherwood number } \\ s_{k} & \text { droplet radius-squared }\left(=\mathrm{r}_{k}^{2}\right), \mathrm{m}^{2} \\ S c & \text { Schmidt number } \\ S M D & \text { Sauter mean diameter, } \mathrm{m} \\ t & \text { time, } \mathrm{s} \\ T & \text { temperature, } \mathrm{K} \\ T_{b} & \text { boiling temperature, } \mathrm{K} \\ T_{k} & \text { kth droplet temperature, } \mathrm{K} \\ U & \text { gas or liquid velocity, } \mathrm{m} / \mathrm{s} \\ x & \text { axial distance, } \mathrm{m} \\ y & \text { radial distance, } \mathrm{m} \\ \Delta p & \text { pressure drop in the injector, } \mathrm{N} / \mathrm{m}^{2} \\ \mu & \text { dynamic viscosity, } \mathrm{kg} / \mathrm{ms} \\ & \end{array}$


$\nu \quad$ kinematic viscosity, $\mathrm{m}^{2} / \mathrm{s}$

$\rho$ density, $\mathrm{kg} / \mathrm{m}^{3}$

$\theta$ spray cone angle, deg.

\section{Subscripts}

$f \quad$ fuel

$g \quad$ gas

inj injector

$l \quad$ liquid

$r$ radial coordinate

$s \quad$ droplet surface

$t$ time

$x \quad$ axial or $\mathrm{x}$-coordinate

$y \quad \mathrm{y}$-coordinate

$z \quad$ z-coordinate

\section{Superscripts}

mean, or average

flow rate

\section{INTRODUCTION}

Flashing phenomena refers to a process that is in thermodynamic non-equilibrium when a liquid is superheated [1-2]. The main reasons for its occurrence are two-fold [1-2]: (1) a liquid fuel can be heated to a temperature above its saturation temperature while its pressure is maintained, and (2) rapid depressurization across a fuel injection system may lead to flash injection because thermal inertia initially tends to maintain its internal liquid temperature above the saturation temperature associated with the lower back pressure. Although flash evaporation is considered to be detrimental to engine performance under normal circumstances, it can have some potential benefits as it is known to produce a fine spray with enhanced atomization, increase effective spray cone angle, and decrease spray penetration [3].

An understanding of flash injection is of importance in some applications involving scramjet and ramjet afterburners because the same liquid fuel is often used as a coolant coupled with engine conditions where nozzles operate at low back pressures and supersonic outflow [3]. Under some gas-turbine conditions, it is estimated that a small fraction of the liquid fuel may be released by flash boiling, and there are some reported incidences of flash-related engine problems in gasoline direct-injection internal combustion engines [4]. The objective of our work is to establish a baseline accuracy for existing atomization and vaporization models valid under superheat conditions by undertaking a critical review of existing experimental data for validation. This work is funded through the NASA's fundamental aeronautics/supersonic initiative: high altitude emissions.

We have started our work with the implementation of a modeling approach based on existing superheat vaporization models into our spray solution procedure [5]. Our previous work on spray calculations can be found in Refs. [5-13] where we have advanced the state of the art in multi-dimensional spray/gaseous combustion calculations in several important ways by combining the novelty of the coupled CFD/spray/scalar Monte Carlo PDF (Probability Density Function) computations with the ability to run on massively parallel computers and unstructured grids.

The modeling approach adopted from the papers of Zuo, Gomes, and Rutland [4] and Schmehl and Steelant [14-15] is based on an extension of the classical $D^{2}$-theory. In the classical evaporation model, the thermal energy needed for evaporation is mostly furnished by the external heat transfer from the surrounding gas. Under superheat conditions, the characteristic vaporization time resulting from the external heat transfer from the surrounding gas is of the same order of magnitude as that resulting from the flash evaporation. The energy needed for vaporization at the droplet surface is partly provided by the superheat energy stored within the droplet but it is controlled by the droplet internal heat transfer. This modeling approach differs from the classical droplet vaporization models in three important ways: (1) the droplet surface mass fraction, $Y_{f s}$, approaches unity as the temperature at the droplet surface remains at the corresponding liquid boiling temperature under superheat conditions; (2) under superheat conditions, all the external heat transfer from the surrounding gas is made available to the vaporization process with no apparent increase in the droplet surface temperature; and (3) the flow of fuel vapor imparted by flash vaporization partly counterbalances the flow generated by external heat transfer which in turn may lead to a decrease in the energy transferred from the surrounding gas.

\section{VAPORIZATION MODEL VALID UNDER SUPERHEAT CONDITIONS}

Based on the governing equations of conservation for an isolated spherically symmetric droplet, 
Zuo et al [4] and Schmehl and Steelant [14-15] showed that the total evaporation rate, $\dot{m}_{k}$, can be calculated as

$$
\dot{m}_{k}=\dot{m}_{k, \text { flash }}+\dot{m}_{k, t}
$$

where the flash boiled vaporization rate, $\dot{m}_{k, f l a s h}$, is given by

$$
\dot{m}_{k, f l a s h}=4 \pi r_{k}^{2} \alpha_{s} \frac{\left(T_{k}-T_{b}\right)}{l_{k}}
$$

where $T_{k}$ is the internal droplet temperature and the overall heat transfer coefficient, $\alpha_{s}\left(=k J / s m^{2}{ }^{\circ} K\right)$ is given by the Adachi correlation [16]:

$$
\begin{aligned}
& =0.76\left(T_{k}-T_{b}\right)^{0.26} \quad\left(0 \leq T_{k s}-T_{b} \leq 5\right) \\
& \alpha_{s}=0.027\left(T_{k}-T_{b}\right)^{2.33} \quad\left(5 \leq T_{k s}-T_{b} \leq 25\right) \\
& =13.8\left(T_{k}-T_{b}\right)^{0.39} \quad\left(T_{k s}-T_{b} \geq 25\right)
\end{aligned}
$$

which is valid over a wide range of superheat conditions. The vaporization rate due to external heat transfer, $\dot{m}_{k, t}$, in Eq. (1) is given by

$$
\dot{m}_{k, t}=2 \pi r_{k} \frac{k}{C_{p}} \frac{N u}{1+\frac{\dot{m}_{k, f l a s h}}{\dot{m}_{k, t}}} \ln \left[1+\left(1+\frac{\dot{m}_{k, f l a s h}}{\dot{m}_{k, t}}\right) B_{t}\right]
$$

where the Spalding heat transfer number, $B_{t}$, is

$$
B_{t}=\frac{C_{p}\left(T_{g}-T_{k s}\right)}{l_{k, e f f}}
$$

and the effective latent heat of vaporization, $l_{k, e f f}$, is given by

$$
l_{k, e f f}=l_{k}+4 \pi \frac{\lambda_{l} r_{k}^{2}}{\dot{m}_{k}}\left(\frac{\partial T_{k}}{\partial r}\right)_{s}
$$

which is an useful parameter as it represents the total energy loss associated with the latent heat of vaporization in addition to the the heat loss to the droplet interior. Finally, the Nusselt number, $\mathrm{Nu}$, and the corresponding droplet regression rate, $\frac{d s_{k}}{d t}$, are given by

$$
\begin{gathered}
N u=2\left(1+0.3 \operatorname{Re}^{1 / 2} \operatorname{Pr}_{g}^{1 / 3}\right) \\
\frac{d s_{k}}{d t}=-\frac{\dot{m}_{k}}{2 \pi r_{k} \rho_{l}}
\end{gathered}
$$

This model is valid over an entire range of superheat conditions as long as there is some amount of superheat energy available within the droplet $\left(T_{k}>\right.$ $\left.T_{b}\right)$.

\section{COMBINED SUPERHEAT-CLASSICAL VAPORIZATION MODEL}

Under moderate initial superheat conditions, only a fraction of the vaporization takes place under superheat conditions $\left(T_{k}>T_{b}\right)$ and the remainder takes place under more stable (non-superheat) evaporating conditions $\left(T_{k} \leq T_{b}\right)$. So there is a need to revert back to a vaporization model valid under stable evaporating conditions when the internal droplet temperature approaches the boiling temperature. In the present calculations, the vaporization rate under normal evaporating conditions is evaluated by means of a simplified classical $D^{2}$-theory:

$$
\dot{m}_{k}=2 \pi r_{k} \rho_{g} D_{f g s} S h \ln \left(1+B_{k}\right)
$$

where the Spalding mass transfer number, $B_{k}$, and the Sherwood number, $S h$, are given by

$$
\begin{gathered}
B_{k}=\frac{\left(y_{f s}-y_{f}\right)}{\left(1-y_{f s}\right)} \\
S h=2\left(1+0.3 R e^{1 / 2} S c_{g}^{1 / 3}\right)
\end{gathered}
$$

where $y_{f s}$ is the mass fraction of the fuel species at the the droplet interface and $y_{f}$ is the mass fraction of the fuel species in the surrounding gas.

\section{INTERNAL DROPLET TEMPERATURE CALCULATION}

Our experience with the validation studies showed us that there is a definite need to include a calculation involving the internal droplet temperature valid under both superheat and normal evaporating conditions. In our present calculations, it was evaluated by means of a simple infinite conductivity model.

$$
\begin{gathered}
\frac{d T_{k}}{d t}=-\frac{3\left[l_{k, e f f}-l_{k}\right]}{2 C_{p l} r_{k}^{2}} \frac{d s_{k}}{d t} \\
\text { if } T_{k} \leq T_{b}, \quad \text { and } \\
\frac{d T_{k}}{d t}=-\frac{3 \alpha_{s}}{r_{k} \rho_{l} C_{p l}}\left(T_{k}-T_{b}\right) \\
\text { if } T_{k}>T_{b}
\end{gathered}
$$




\section{VALIDATION RESULTS}

We have spent considerable time on the literature survey in trying to identify some relevant experimental data for validation purposes. Of the limited data available, the recent experimental investigation by Yildiz et al $[1-2,19]$ seems to be more promising as it contained data for two-phase jet flows associated with the near-field flashing phenomena generated by the sudden release of pressurized R134A from nozzles of different sizes with orifice-exit diameters ranging from 1,2 , and $4 \mathrm{~mm}$. The experiments were performed mainly to simulate the effects of flashing phenomena generated by either of pressurized propane or butane. The reported data contained the particle image velocimetry (PIV) measurements of gas and droplet velocities, the phase doppler anemometry (PDA) measurements of droplet sizes, the thermocouple measurements of temperatures, and the high speed images of flow visualization. While the data appeared to be worth pursuing, the reported experimental data contained a great deal of uncertainty with respect to the specification of the initial conditions. It is also noteworthy that the data had not gone through a rigorous review in terms of its applicability for validation purposes.

In the VKI experiments [1-2,19], the overall superheat conditions ranged between 40 to $50^{\circ} \mathrm{C}$ and the tank pressure ranged between 700 to $942 \mathrm{KPa}$ [17]. For the conditions considered, the onset of jet breakup was observed to occur outside of the nozzleexit between $2-27 \mathrm{~mm}$ for the $1 \mathrm{~mm}$ nozzle, and 4-20 $\mathrm{mm}$ for the $2 \mathrm{~mm}$ nozzle. But for the $4 \mathrm{~mm}$ nozzle, a cloudy behavior was observed starting at $12 \mathrm{~mm}$ with no discernable point of jet disintegration [17]. Our CFD calculations are focused primarily on predicting the flow characteristics further downstream beginning with the onset of jet breakup. At the start of jet dispersion, the pressurized liquid would undergo some expansion due to vaporization of the pressurized liquid depending on the degree of superheat and the entrainment of surrounding air [17]. Because of this expansion, the effective size of the expanded jet would be larger than the orifice exit [17]. Therefore, there is a need for estimating both the size and expansion angle of the jet from the observed experimental data [17].

In our present calculations, we have focused mainly on the case involving the $1 \mathrm{~mm}$ nozzle for which the most extensive data were reported. For this case, the initial liquid temperature is $293 \mathrm{deg}$. $\mathrm{K}$ which corresponds to a superheat temperature of $46 \mathrm{deg}$. C. The initial liquid stagnation velocity is estimated to be about $34 \mathrm{~m} / \mathrm{s}$ based on the given upstream and back pressures. Based on the data and the assumptions discussed in Ref. [17], the initial size at the flashing point is estimated to be about $9 \mathrm{~mm}$ based on an initial expansion angle of 55-60 from $\mathrm{X}=1$ to $3 \mathrm{D}$.

Our computations were performed by making use of a single-point droplet injection with a solid cone angle of $6.0 \mathrm{deg}$. The spray injection is simulated by making use of five droplet streams. The droplets for each stream were injected randomly within a predefined angular segment (interval spacing $=1.25 \mathrm{deg}$ ) of the solid cone angle (=6.0 deg) at different droplet injection time steps. Within each droplet stream, the droplet size distribution is calculated by means of a known droplet correlation but it is represented by making use of five droplet size groups. Further details of the spray injection can be found in Ref. [5]. From the reported data on droplet count it is difficult to estimate the precise nature of the droplet size distribution at $\mathrm{x} / \mathrm{D}=14$ (the point of jet breakup) [1-2,19]. But based on the $D_{32}$ (SMD) measurements taken at the next nearest location $(\mathrm{x} / \mathrm{D}=110)$, most of the droplet count ranges between 40 to 220 microns [17]. In light of this uncertainty, we have performed three different calculations to assess the effect of the initial droplet size distribution on the ensuing flowfield:

1. In our first calculation (Case 1), we assumed that the initial droplet distribution could be represented by the widely-used droplet size correlation of Whitelaw and Banhawy [18]. For an initial SMD of 93 microns. the droplet size distribution yields the following sizes $\left(D_{32}\right)$ for the five droplet groups: $38.31,80.73,134.89,190.45$, and 246.32 microns. It is noteworthy that the mass flow rate associated with each group is the same, and the droplet size distribution is assumed to be the same amongst all the five droplet streams. This distribution yields slightly larger droplet sizes than those present at $\mathrm{x} / \mathrm{D}=110$.

2. In the second calculation (Case 2) the initial droplet size-range was chosen to be similar to that reported at $\mathrm{x} / \mathrm{D}=110$. This was achieved by decreasing the initial SMD from 93 to 80 microns and the corresponding size distribution yields the following sizes $\left(D_{32}\right): 32.95,69.43$, $116.02,163.82$, \& 211.87 microns. This calculation was performed mainly to determine the 
effect of the initial SMD on the calculated results.

3. In the third calculation (Case 3), the initial droplet conditions are prescribed based on a more realistic approach as it takes into account the need to have more larger droplets in the middle of a cylindrical jet near the point of jet breakup. In constructing the droplet size distribution for this calculation, we made use of the sizes derived from Case 2. In the inner region of 4.5 deg., the size distribution is assumed to be made up of $116.02,163.82$, \& 211.87 microndroplets with the corresponding mass flow rates given by $13,40, \& 47 \%$. In the outer half-cone angle between 4.5 to 6 deg., the size distribution is assumed to be the same as in Case 2 . This was done mainly to adjust the size distribution with the observed experimental behavior which seemed to show droplets of 100 microns and above representing a significant percentage of the total mass flow rate.

All the calculations were performed on a $2 \mathrm{D}$ axisymmetric grid with 79101 triangular elements. The calculations were advanced until a steady state solution was reached by making use of the following time steps: $\Delta t_{g}$ (= local time step used in the flow solver, s) was determined based on a CFL number of $1, \Delta t_{\text {injection }}$ (time-step at which a new group of droplets is introduced) $=2.0 \mathrm{~ms}$, and $\Delta t_{k}$ (time step used in the spray solver) $=0.0075 \mathrm{~ms}$. The initial gas conditions were prescribed based on the nondimensional velocity profile reported in Ref. [5]. The initial droplet injection velocity and the initial liquid temperature are taken to be $34 \mathrm{~m} / \mathrm{s}$ and $293 \mathrm{deg} . \mathrm{K}$, respectively.

First, we would like to show the observed and predicted spray patterns. Fig. 1 shows an experimental photograph obtained by means of a highspeed photography for the two-phase flashing jet generated by a $1 \mathrm{~mm}$ nozzle (taken from Yildiz et al [19]). The corresponding axisymmetric spray pattern as predicted by our CFD computations for Case 3 is shown in Fig. 2. It is also noteworthy that there is no direct correspondence in the scales used between the experiments and predictions. The results from the other two calculations are similar to Case 3.

\section{Gas Velocity Comparisons}

In this section, we show the gas velocity comparisons between the experimental data and predictions in the form of non-dimensional velocity profiles. The velocity is non-dimensionalized by means of $U / U_{\max }$ and the radial distance by $r / D /(r / D)_{U_{\max } / 2}$.

The experimental data represents the combined data taken from all the experiments performed at various axial locations. It is noteworthy that the reported gas velocities are actually based on the measured velocities of the smallest droplets (of sizes $<10$ $\mu \mathrm{m})$ with the assumption they represent the gas flow. The non-dimensional velocity profiles from the experimental data tend to show a remarkably self-similar behavior with the following correlation [2]:

$$
\frac{U}{U_{\max }}=\exp \left[-0.693\left(\frac{r}{\bar{r}}\right)^{2}\right]
$$

where $\bar{r}=r\left(U_{\max } / 2\right)$. This behavior is noted to be similar to the correlations reported in the literature for single-phase turbulent jets and two-phase jets [20$22]$.

The comparisons for Case 1 to 3 are shown in Figs. 3a to 3c, respectively. Shown here are the comparisons between the experimental data, the experimental correlation from Eq. (14), and the CFD predictions for each one of the three axial locations at $\mathrm{x} / \mathrm{D}=110,220$, and 440 . For all the cases the predictions fall entirely within the scatter range of the experimental data. However, outside of the experimental range the CFD results overpredict the gas velocity given by Eq. (14). Also, the predicted results exhibit a general trend where the radial spreading of gas velocity mostly increases with an increase in the axial distance.

\section{Droplet Size Comparisons}

Here, we provide the comparisons for the radial profiles of droplet sizes as given by local SMD $\left(D_{32}\right)$ versus non-dimensional radial distance, $r / D$. Figs. 4a-c provide the comparisons for Case 1 at three axial locations, $x / D=110,220$, and 440. Similar comparisons for the other two cases are provided in Figs. 5a-c and 6a-c.

As can be seen from the experimental data in Figs. 4-6, the droplet sizes are larger at the center (axis) and they decrease in size in the radial direction [2]. From the comparisons of the profiles at $\mathrm{x} / \mathrm{D}=$ 220 and $\mathrm{x} / \mathrm{D}=440$, the experimental data exhibit a general trend where the overall droplet size distribution seemed to increase with an increase in the axial distance. This effect was attributed for reasons associated with faster evaporation of smaller droplets [2]. 
The predictions from Figs. 4a-c for Case 1 show a trend that is clearly opposite to the experimental data. The CFD results show for the larger droplets to be located farther away from the center. To understand the reasons for this behavior, it helps to recall that the initial size distribution in Case 1 is assumed to be uniform in all directions and made up of five droplet classes with sizes $\left(D_{32}\right)$ ranging from $38.31,80.73,134.89,190.45$, and $246.32 \mu \mathrm{m}$. This distribution seemed to contain a lot more smaller droplets than in the experiments. As a result, some of the smaller droplets, especially those located near the center, are swept downstream towards the middle where the gas velocity is higher (Figs. 3a-c). While smaller droplets move near the cnter, the larger droplets with higher momentum seem to move radially outwards. The combined effect of which is to produce a trend that is in odds with the experimental data. The overall trends in Figs. 5a-c for Case 2 are similar to Figs. 4a-c for Case 1. The main difference between the two cases is due the changes made to the size distribution where the initial SMD was reduced from 93 microns in Case 1 to 80 microns in Case 2.

Unlike the first two calculations, the predicted trends in Figs. 6a-c for Case 3 are more in line with the experimental data. It is because the initial droplet size distribution takes into account the need to have more larger droplets in the middle of a cylindrical jet. It is noteworthy of the remarkable shift in the overall predicted trends with the changes made to the initial size distribution from Cases 1 and 2 to Case 3 .

\section{Droplet Velocity Comparisons}

Shown in Figs. 7a-c to 9a-c are the nondimensional droplet velocity profiles for Cases 1 to 3 , respectively. Once again the velocity is nondimensionalized by $U / U_{\max }$, and the radial distance by $r / D /(r / D)_{U_{\max } / 2}$. It is noteworthy that the experimental velocity data of Yildiz et al [2] also exhibit a self-similar behavior as in the gas velocity comparisons given by Eq. (14). The normalized experimental data represents the combined data taken from all the axial locations by the PDA mesuarements for all droplets with sizes greater than $10 \mu \mathrm{m}$. It is not entirely evident as to why the velocities for both gas phase and the droplets follow the same correlation as given by Eq. (14).

Some noteworthy aspects of the comparisons from Figs. 7a-c to 9a-c are as follows: (1) The CFD results show a general trend similar to the experimental data but exhibit a wider scatter than the experiments. (2) The results from Case 3 are in better agreement than Cases 1 and 2 as more of its predicted velocities (Case 3) fall within the experimental range. (3) In all the cases at $\mathrm{x} / \mathrm{D}=110$, most of the predicted velocities are found to be located in the upper range of the experimental data because of the way we specified the initial conditions where the injection velocity for all droplets was assumed to be uniform and given by $34 \mathrm{~m} / \mathrm{s}$. But the predicted velocity range improves considerably at the the last two axial locations. (5) The scatter in the predicted velocities seems to be slightly more pronounced at $\mathrm{x} / \mathrm{D}=440$.

\section{Temperature Comparisons}

As for the temperature comparisons, it is not possible in making any direct comparisons between the predicted gas and liquid temperatures and the experimental data. To understand the reasons behind it, we provide some details on the nature of the temperature measurements provided by Ref. [19]. The steady-state temperature measurements as measured by a thermocouple made up of Chrome/Alumel wire of $0.2 \mathrm{~mm}$ diameter represents an aggregate (liquidgas) temperature. Therefore, its usefulness in making direct comparisons with either gas or liquid temperatures obtained from the CFD calculations becomes difficult. This consideration becomes more evident when we look at Fig. 10 showing the single-point thermocouple temperature signal in time taken from Ref. [19]. Initially, the thermocouple registers a temperature of $293 \mathrm{deg}$. K (= ambient gas temperature) before it reaches a steady-state temperature of 248.7 deg. $K$ ( $\approx$ the boiling temperature of $\mathrm{R} 134 \mathrm{~A})$. Also, because of the intrusive nature of the technique (taken by a thermocouple rack), the reported temperatures represent an aggregate temperature in the neighborhood of the centerline. For the reasons given, no effort was made in making any direct comparisons with the experimental data.

Fig. 11 shows the axial (centerline) variation of the measured thermocouple temperatures as well as the predicted gas and liquid temperatures for Case 3. The liquid temperatures are shown in terms of both individual as well as average droplet temperatures. The predicted gas temperatures follow the measurements after falling from an initial ambient temperature of about $296^{\circ} \mathrm{K}$ to about $235^{\circ} \mathrm{K}$ at $\mathrm{x} / \mathrm{D}=$ 10. On the other hand, the average droplet temperatures overpredict the measured temperatures initially 
before falling below the experimental data further downstream. The comparisons between the gas and average droplet temperatures show that some of the droplets located near the centerline vaporize under conditions where the surrounding gas temperature is below the average droplet surface temperature. The results from the other two calculations are similar to Case 3.

\section{CONCLUDING REMARKS}

For the case considered, it is reasonable to conclude that the present CFD vaporization models are capable of providing a reasonable qualitative description for the two-phase jet characteristics generated by the sudden initial release of a superheated fuel. However, there exists a definite uncertainty with regard to the specification of the initial conditions used in our spray computations. Because of the uncertainty associated with the specification of the initial conditions, there is a definite need to assess and establish the accuracy of the existing atomization models in the calculation of superheated sprays. The predictions show that some droplets vaporize under superheated conditions but others vaporize after transitioning to a stable vaporization regime. But there is a need for experimental data on separate gas and liquid temperatures in order to validate the vaporization models based on the Adachi correlation for a liquid involving R134A.

\section{REFERENCES}

1. Yildiz, D., Rambaud, P., Van Beeck, J., Buchlin, J.-M., "Characterization of Superheated Liquid Jet Atomization Phase Doppler Anemometer (PDA) and High-Speed Imaging," Proceedings of FEDSM2006: 2006 ASME Joint U.S.European Fluids Engineering Summer Meeting, July 17-20, 2006, Miami, Florida.

2. Yildiz, D., Rambaud, P., Van Beeck, J., Buchlin, J.-M., "Evolution of the Spray Characteristics in Superheated Liquid Jet Atomization in Function of Initial Flow Conditions," ICLASS-2006, Paper ID ICLASS06-122, Aug. 27-Sept 1, 2006, Kyoto, Japan.

3. Lucas, K.D., Tseng, C.C., Pourpoint, T.L., Lucht, R.P., and Anderson, W.E., "Imaging Flashing Injection of Acetone at Jet Engine Augmentor Conditions," AIAA Paper 2007-1182, 45th AIAA Aerospace Sciences Meeting and Exhibit, Reno, Nevada, Jan. 8-11, 2007.
4. Zuo, B., Gomes, A.M., and Rutland, C.J., "Modeling Superheated Fuel Sprays and Vaporization," Int. J. Engine Research, vol. 1, no. 4, pp. 321-336.

5. M.S. Raju, LSPRAY - A Lagrangian Spray Solver - User's Manual, NASA/CR-97-206240, NASA Lewis Research Center, Cleveland, Ohio, November 1997.

6. M.S. Raju, EUPDF - An Eulerian-Based Monte Carlo Probability Density Function (PDF) Solver - User's Manual, NASA/CR-1998-20401, NASA Lewis Research Center, Cleveland, Ohio, April, 1998.

7. Raju M.S., and Sirignano, W.A., "MultiComponent Spray Computations in a Modified Centerbody Combustor," Journal of Propulsion and Power, Vol. 6, No. 2, March-April 1990.

8. Raju, M.S., "AGNI-3D: A Computer Code for the Three-Dimensional Modeling of a Wankel Engine," Computers in Engine Technology, Proceedings IMechE, London, United Kingdom, pp. 27-37, 1991.

9. Raju, M.S., "Heat Transfer and Performance Characteristics of a Dual-Ignition Wankel Engine," Journal of Engines, the 1992 SAE Transactions, Section 3, pp. 466-509.

10. M.S. Raju, Application of Scalar Monte Carlo Probability Density Function Method For Turbulent Spray Flames, Numerical Heat Transfer, Part A, vol. 30, pp. 753-777, 1996.

11. M.S. Raju, Current Status of the Use of Parallel Computing in Turbulent Reacting Flows: Computations Involving Sprays, Scalar Monte Carlo Probability Density Function \& Unstructured Grids, Advances in Numerical Heat Transfer, vol. 2, ch. 8, pp.259-287, 2000.

12. M.S. Raju, Scalar Monte Carlo PDF Computations of Spray Flames on Unstructured Grids With Parallel Computing, Numerical Heat Transfer, Part B, No. 2, Vol. 35, pp. 185-209, March 1999.

13. M.S. Raju, On the Importance of Chemistry/Turbulence Interactions in Spray Computations, Numerical Heat Transfer, Part B: Fundamentals, No. 5, Vol. 41, pp. 409-432, 2002. 
14. Schmehl, R, and Steelant, J., "Flash-Evaporation of Oxidizer During Start-Up of an Upper-Stage Rocket Engine," AIAA Paper 2003-5075, 39th AIAA/ASME SAE/ASEE Joint Propulsion Conference and Exhibit, Huntsville, Alabama, July 20-23 2003.

15. Schmehl, R, and Steelant, J., "Evaluation of Oxidizer Temperature Drop in a Combustion Chamber," 4th International Conference on Launcher Technology "Space Launcher Liquid Propulsion, Liege, Belgium, December 3-6 2002.

16. Adachi, M., McDonnel, V.G., Tanaka, D., Senda, J, and Fujimoto, H., "Characteristics of Fuel Vapor Concentration Inside a Flash Boiling Spray," SAE Paper 970871, 1997.

17. "CFD Modeling of Flashing Jet Dispersion," Fluids Mechanics Research Group, University of Hertfordshire, United Kingdom, FLIE ReportFeb. 2005.
18. Y. El Banhawy and J.H. Whitelaw, Calculation of the Flow Properties of a Confined KeroseneSpray Flame, AIAA J., vol. 18, no. 12, pp. 1503-1510, 1980.

19. Yildiz, D., Rambaud, P., Van Beeck, J., Buchlin, J.-M., "A Study on the Dynamics of a Flashing Jet," Von Karman Institute for Fluid Mechanics, Final Contract Research ReportEAR0030/2002.

20. Hetsroni, G., and Sokolov, M., "Distribution of Mass, Velocity, and Intensity of Turbulence in a two-phase Turbulent Jet," J. Appl. Mech., vol. 32, pp.315, 1971.

21. Pope, S.B., "Turbulent Flows," Cambrige University Press, 2000.

22. Bayvel, L.P., and Orzchowski, Z, " Liquid Atomization," Taylor \& Francis, Combustion: An International Series, !st edition, 1993. 


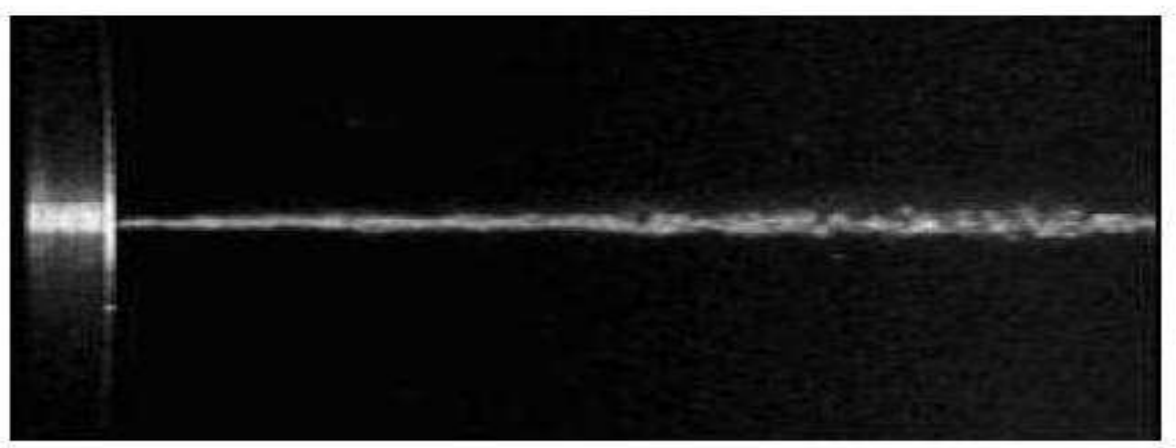

Fig. 1. R134-A Jet under $700 \mathrm{kPa}$ at $23 \mathrm{deg}$. $\mathrm{C}$ for the $1 \mathrm{~mm}$ nozzle (taken from Yildiz et al [19]).

Fig. 2. An axisymmetric view of the predicted spray pattern for the $1 \mathrm{~mm}$ nozzle (Case 3). 

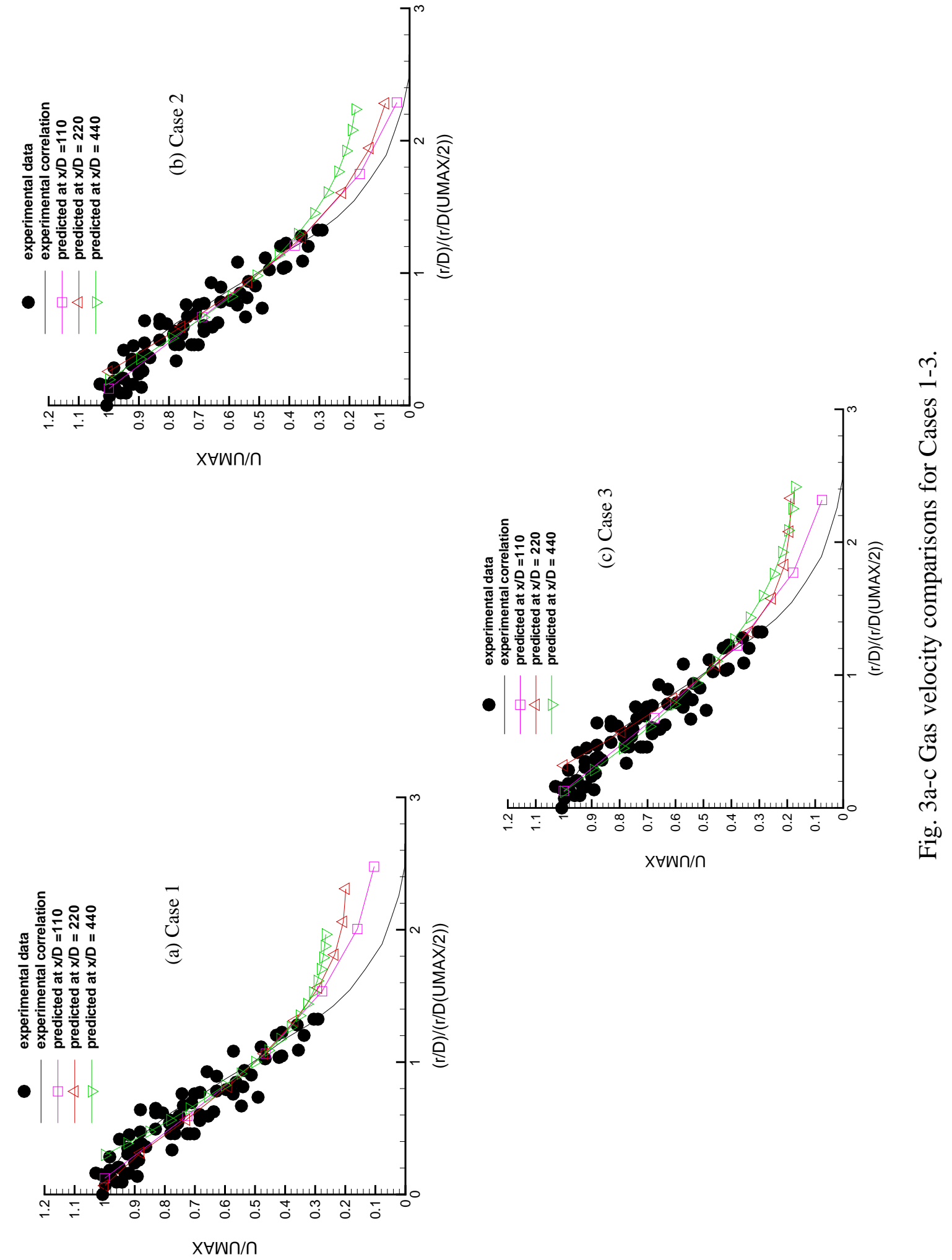

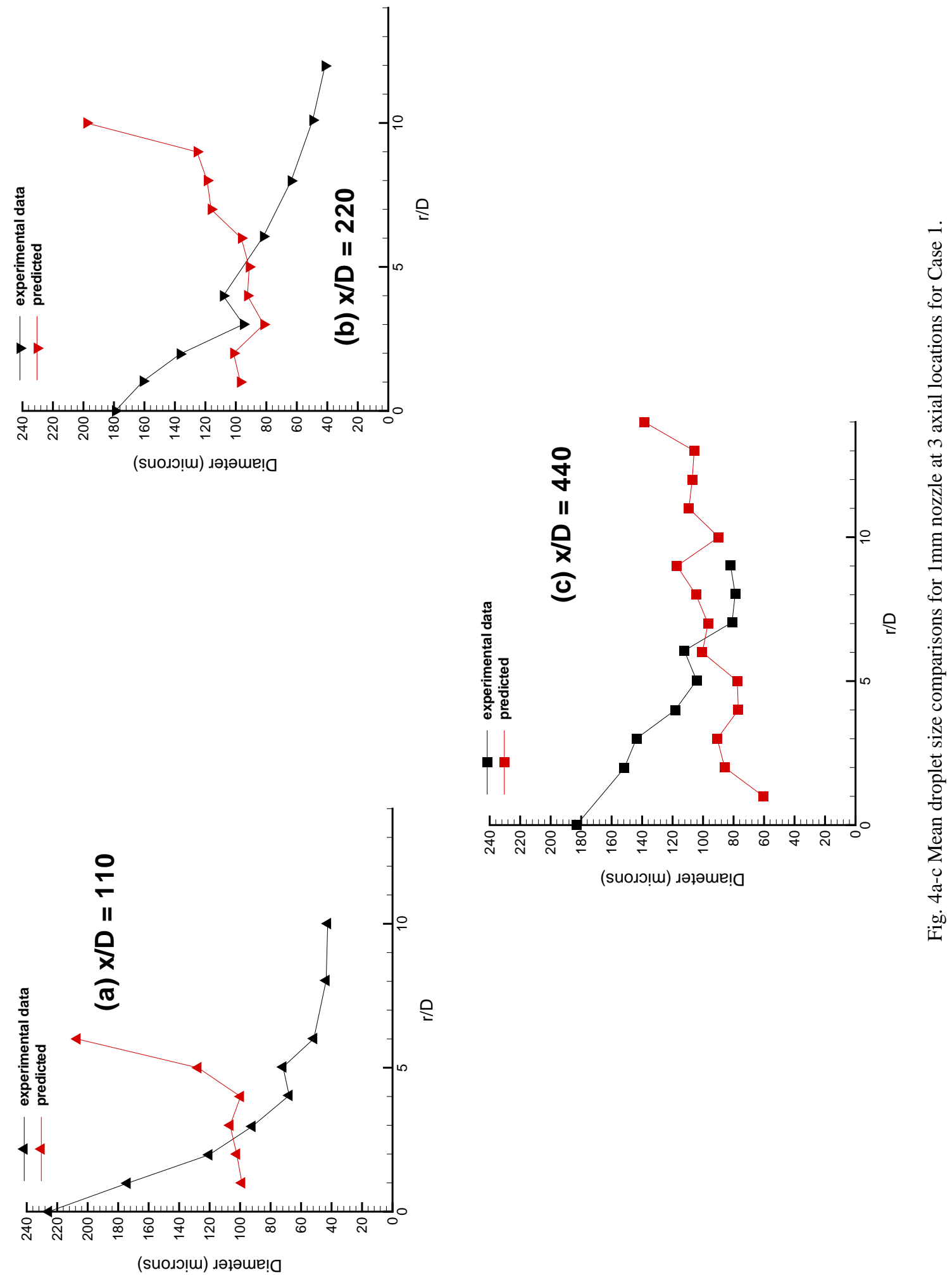

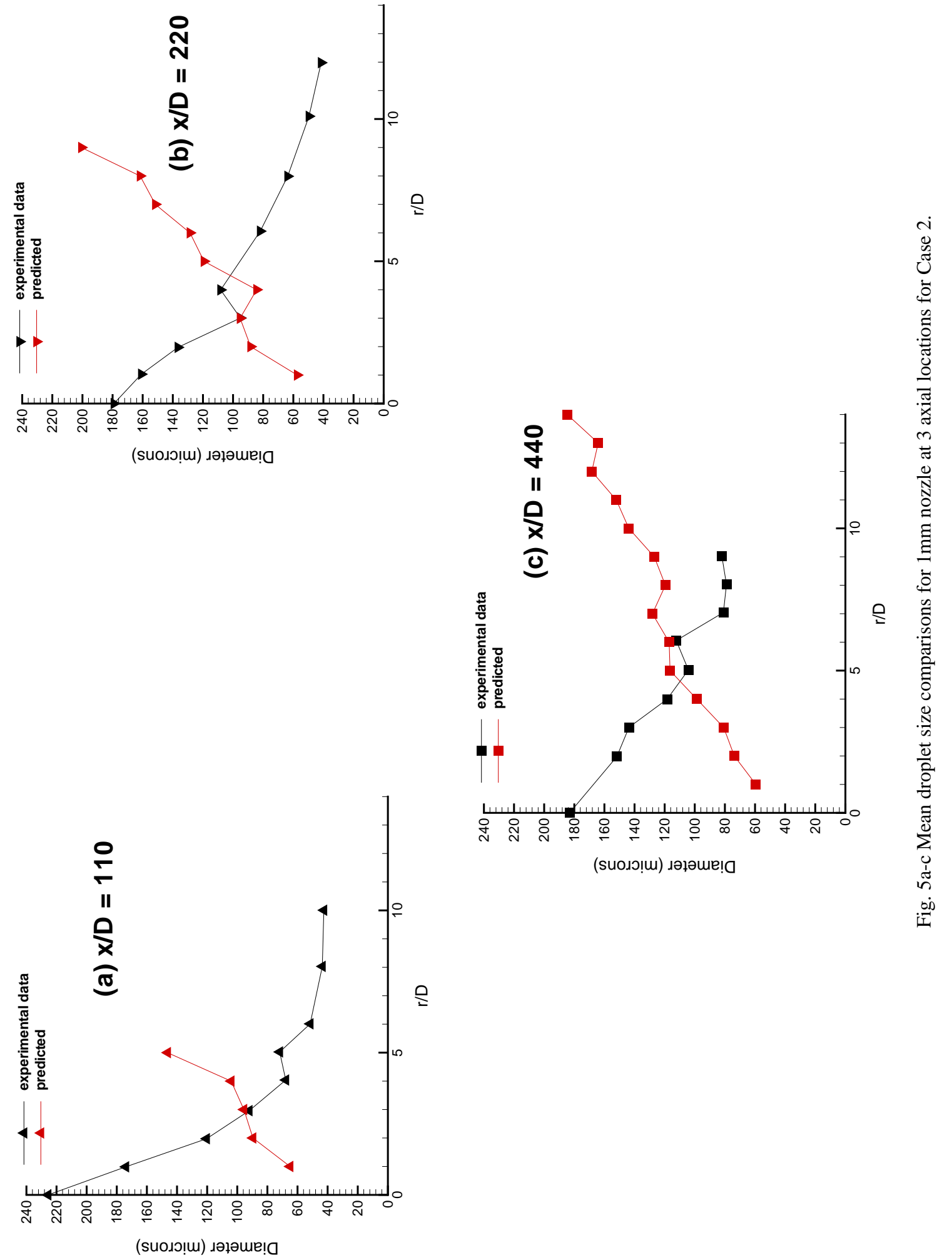

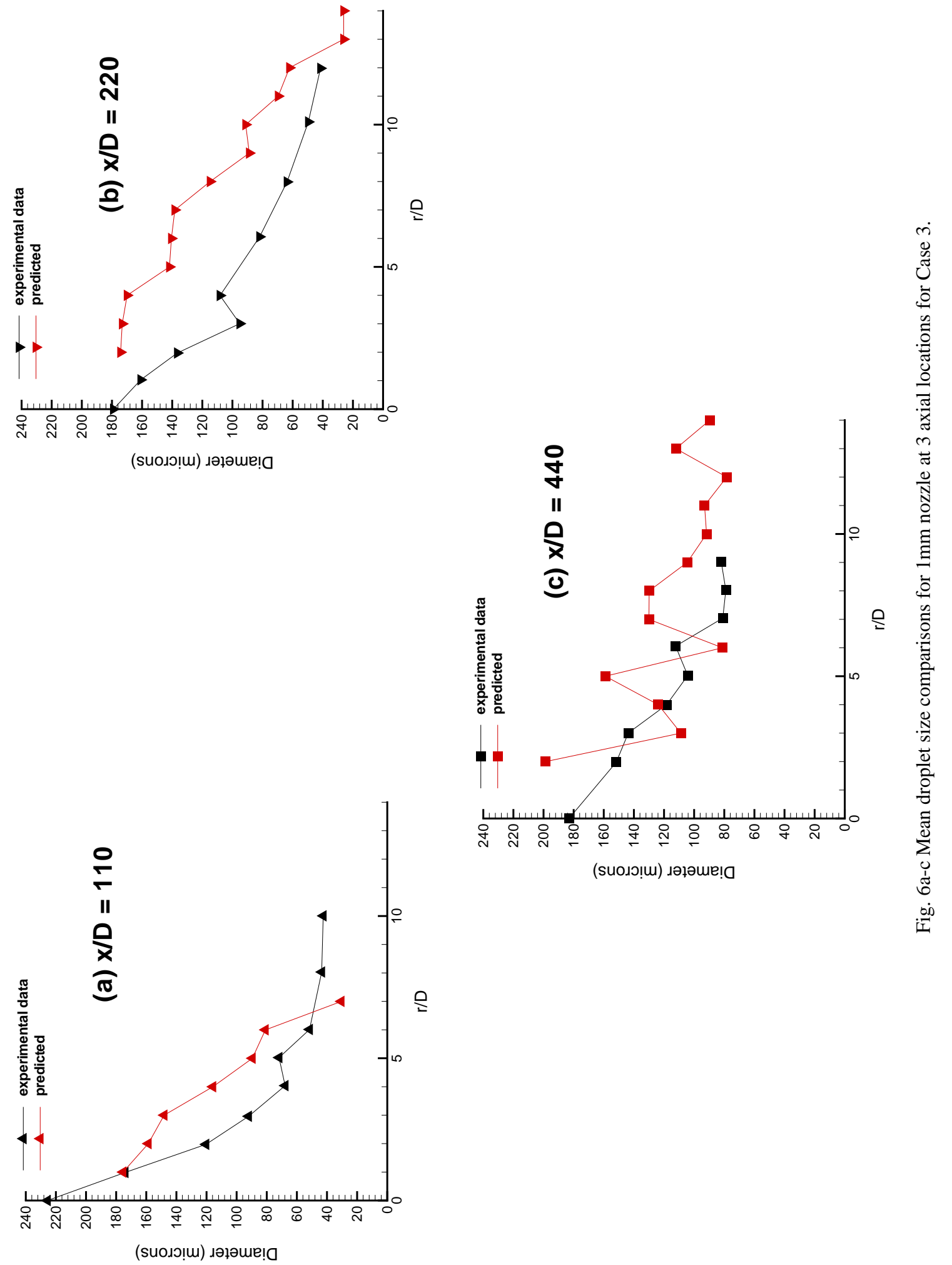

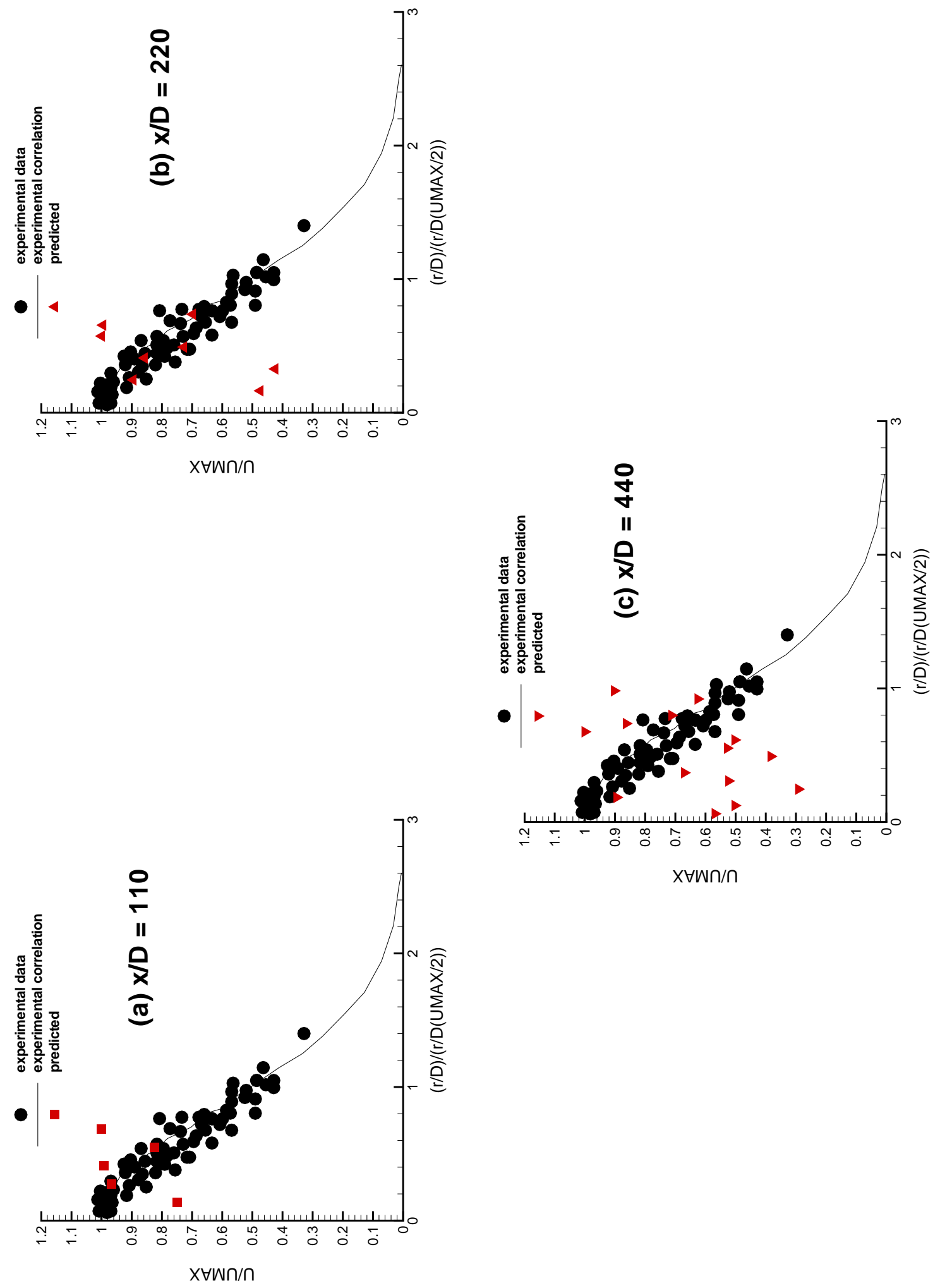

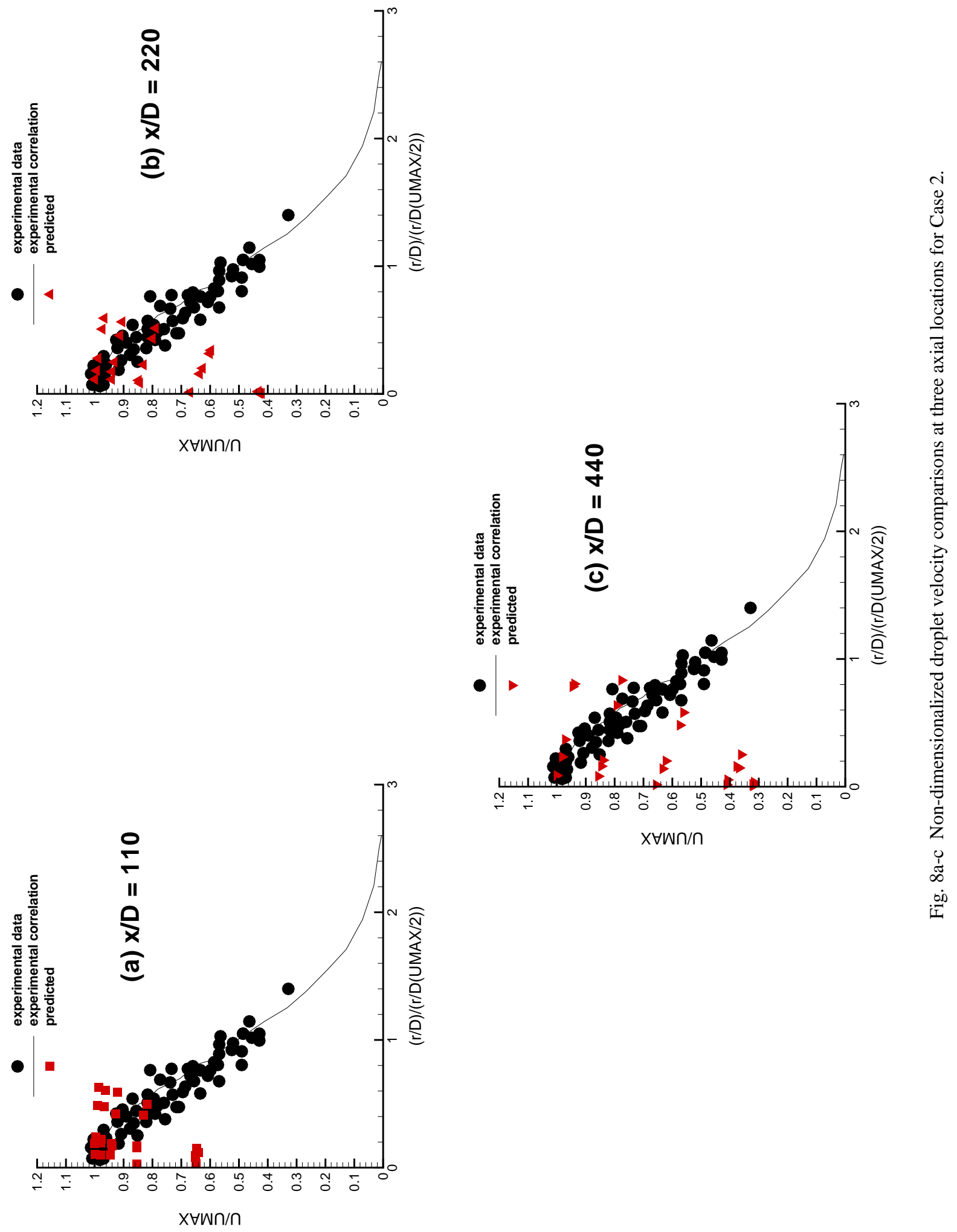

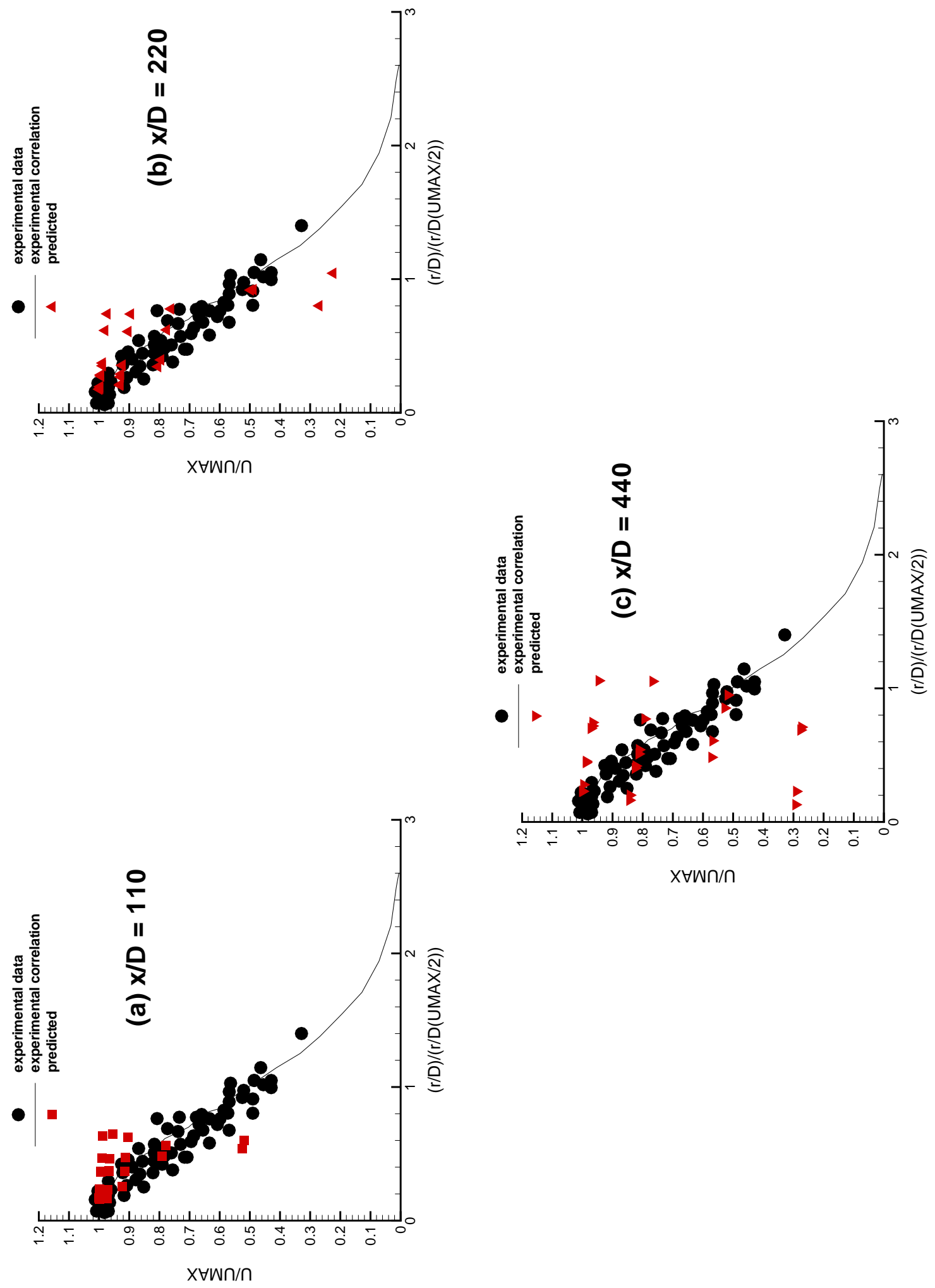


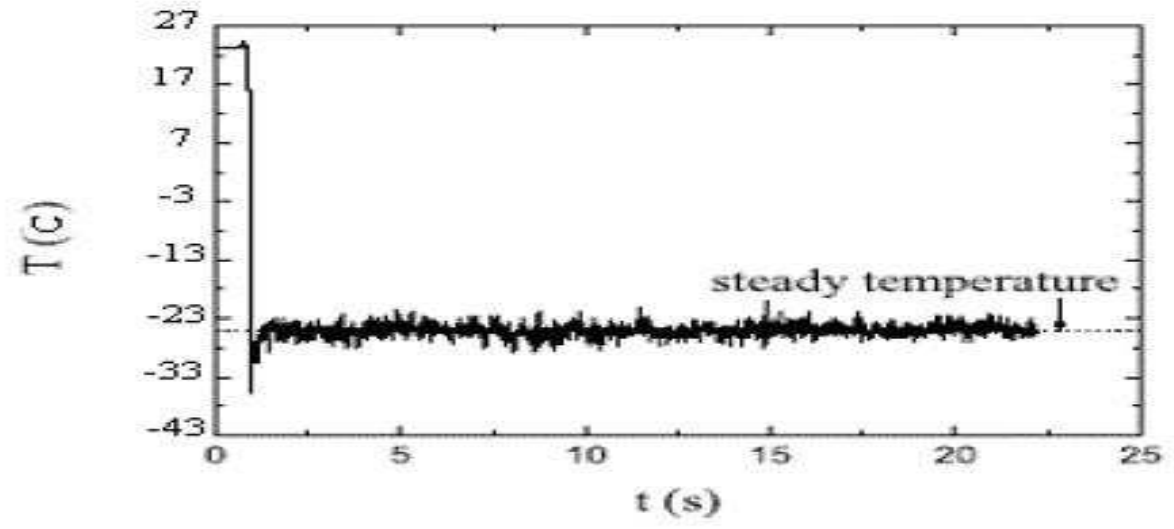

Fig. 10 Temperature signal in time from the thermocouple measurement (taken from Yildiz et al [19]). 


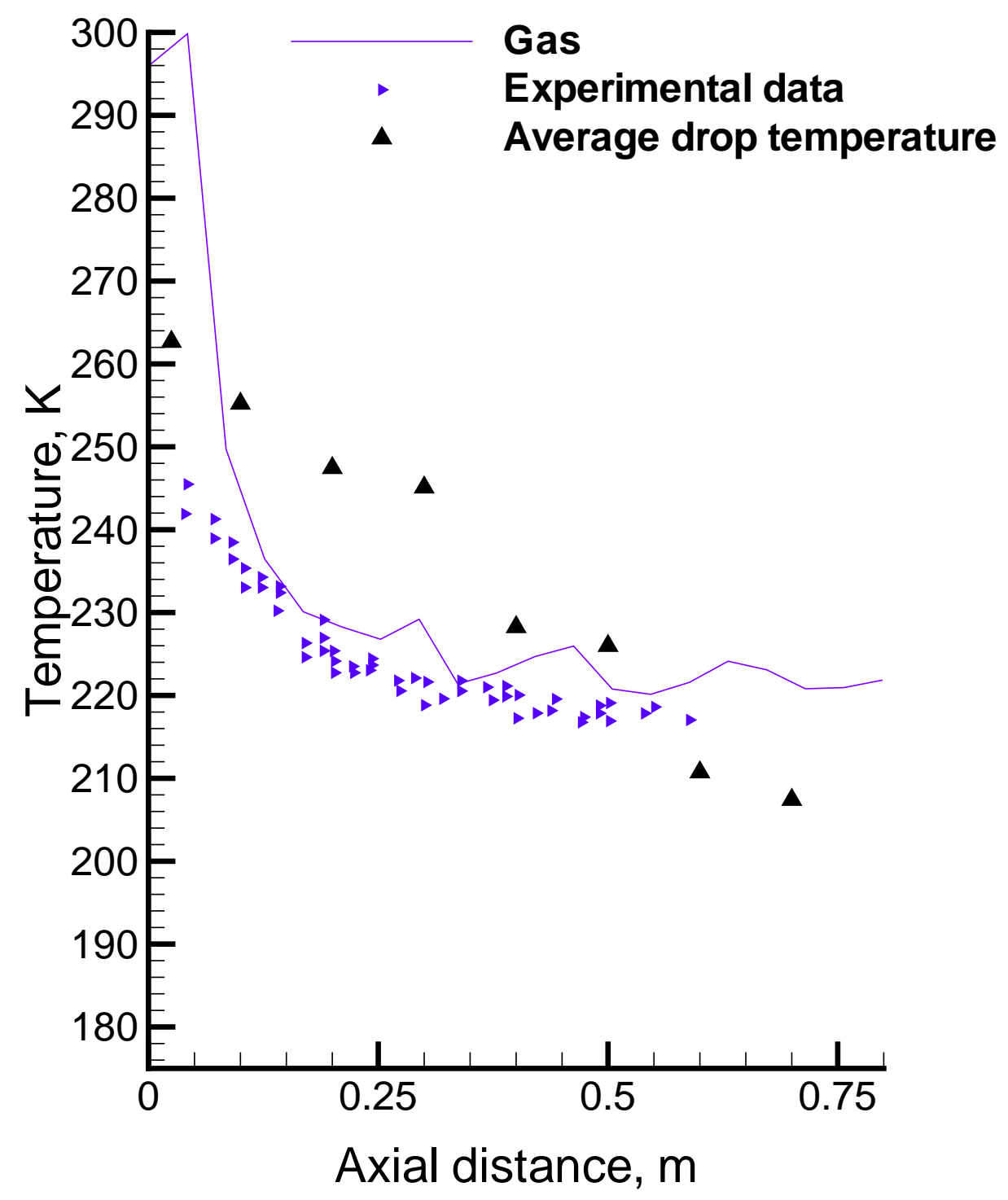

Fig. 11 Axial variation of temperature near the center (axis) for Case 3. 


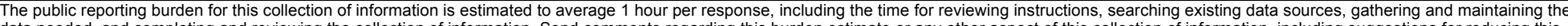

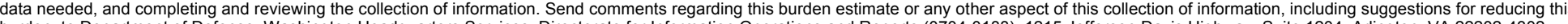

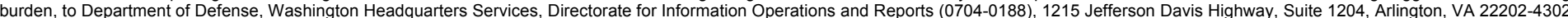

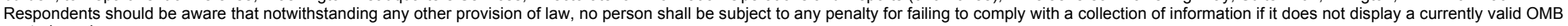
control number.

PLEASE DO NOT RETURN YOUR FORM TO THE ABOVE ADDRESS.

\section{REPORT DATE (DD-MM-YYYY) \\ 2. REPORT TYPE \\ 3. DATES COVERED (From - To)}

01-09-2008

Final Contractor Report

\section{TITLE AND SUBTITLE}

CFD Modeling of Superheated Fuel Sprays

5a. CONTRACT NUMBER

5b. GRANT NUMBER

NNC06BA07B

5c. PROGRAM ELEMENT NUMBER

\section{AUTHOR(S)}

Raju, M.S.

\section{5d. PROJECT NUMBER}

5e. TASK NUMBER

22

5f. WORK UNIT NUMBER

WBS 984754.02.07.03.19.02

\section{PERFORMING ORGANIZATION} REPORT NUMBER

E-16563

ASRC Aerospace Corporation

Cleveland, Ohio 44135

10. SPONSORING/MONITORS
ACRONYM(S)
NASA
11. SPONSORING/MONITORING
REPORT NUMBER
NASA/CR-2008-215289

\section{DISTRIBUTION/AVAILABILITY STATEMENT}

Unclassified-Unlimited

Subject Categories: 07, 28, 34, and 61

Available electronically at http://gltrs.grc.nasa.gov

This publication is available from the NASA Center for AeroSpace Information, 301-621-0390

\section{SUPPLEMENTARY NOTES}

\section{ABSTRACT}

An understanding of fuel atomization and vaporization behavior at superheat conditions is identified to be a topic of importance in the design of modern supersonic engines. As a part of the NASA aeronautics initiative, we have undertaken an assessment study to establish a baseline accuracy of existing CFD models used in the evaluation of a flashing jet. In a first attempt towards attaining this goal, we have incorporated an existing superheat vaporization model into our spray solution procedure but made some improvements to combine the existing models valid at superheated conditions with the models valid at stable (nonsuperheat) evaporating conditions. Also, the paper reports some validation results based on the experimental data obtained from the literature for a superheated spray generated by the sudden release of pressurized R134A from a cylindrical nozzle. The predicted profiles for both gas and droplet velocities show a reasonable agreement with the measured data and exhibit a self-similar pattern similar to a correlation reported in the literature. Because of the uncertainty involved in the specification of some initial conditions, we have investigated the effect of initial droplet size distribution on the validation results. For the case considered, it is reasonable to assume that the present vaporization models are capable of providing a reasonable qualitative description for the two-phase jet characteristics generated by a flashing jet. However, there remains some uncertainty with regard to the specification of certain initial spray conditions.

15. SUBJECT TERMS

CFD; Spray modeling; Combustion; Atomization modeling; Flash vaporization; Superheat vaporization; Reacting flow modeling

\begin{tabular}{|c|c|c|c|}
\hline \multicolumn{3}{|c|}{ 16. SECURITY CLASSIFICATION OF: } & \multirow{2}{*}{$\begin{array}{l}\text { 17. LIMITATION OF } \\
\text { ABSTRACT } \\
\text { UU }\end{array}$} \\
\hline $\begin{array}{l}\text { a. REPORT } \\
\text { U }\end{array}$ & $\begin{array}{l}\text { b. ABSTRACT } \\
U\end{array}$ & $\begin{array}{l}\text { c. THIS } \\
\text { PAGE } \\
\text { U }\end{array}$ & \\
\hline
\end{tabular}

18. NUMBER
OF
PAGES
24

19a. NAME OF RESPONSIBLE PERSON STI Help Desk (email:help@sti.nasa.gov) 19b. TELEPHONE NUMBER (include area code) 301-621-0390 

